\title{
EXTRAÇÃO DO R-(+)-LIMONENO A PARTIR DAS CASCAS DE LARANJA: AVALIAÇÃO E OTIMIZAÇÃO DA VERDURA DOS PROCESSOS DE EXTRAÇÃO TRADICIONAIS
}

Tânia C. M. Pires", Maria Gabriela T. C. Ribeiro*,a e Adélio A. S. C. Machado ${ }^{\text {b }}$

aLAQV/REQUINTE, Departamento de Química e Bioquímica, Faculdade de Ciências da Universidade do Porto, Rua do Campo Alegre 687, Porto 4169-007, Portugal

bDepartamento de Química e Bioquímica, Faculdade de Ciências da Universidade do Porto, Rua do Campo Alegre 687, Porto 4169-007, Portugal

Recebido em 29/07/2017; aceito em 04/09/2017; publicado na web em 27/10/2017

\begin{abstract}
EXTRACTION OF R-(+)-LIMONENE FROM ORANGE PEELS: ASSESSEMENT AND OTIMIZATION OF THE GREENNESS OF TRADITIONAL EXTRACTION PROCESSES. This article reports a study, performed in educational context, to increase the greenness of the extraction of R-(+)-limonene from orange peels. Protocols from the literature were evaluated with the green star (GS) metric and new protocols, based in them, were designed to increase the overall greenness. These were tested in the laboratory and their greenness was assessed by traditional greenness metrics and metrics inspired in the industrial activity. Results showed that the steam distillation technique presents the largest overall greenness when evaluated by the GS, because organic solvents are not involved, but mass and energy metrics indicate that the extractions by solvent techniques are greener. This conflict denotes the complexity of the concept of chemical greenness and the need of using several types of metrics when greenness evaluation is at stake. The results show that the inclusion of experiments on the R-(+)-limonene extraction in the educational laboratory is efficient to show the difficulties of assessing the greenness of chemistry and of implementing Green Chemistry.
\end{abstract}

Keywords: green metrics; green chemistry education; greenness improvement; limonene; orange oil.

\section{INTRODUÇÃO}

A escassez de recursos naturais e a ameaça de problemas ambientais, tanto a elevada produção de resíduos, muitos dos quais tóxicos, como os efeitos dos poluentes decorrentes da atividade humana, requerem modalidades inovadoras de implementação da química com menos impactos sobre o ambiente. ${ }^{1,2}$ Como consequência, nos últimos anos, observa-se um interesse crescente no uso de matérias-primas renováveis que possam ser uma alternativa aos recursos fósseis convencionais, contribuindo para a criação de um novo paradigma na indústria química, a bioindústria. ${ }^{1,3} \mathrm{~A}$ bioindústria inova relativamente à indústria convencional através da utilização de biomassa e respetivos resíduos como matéria-prima renovável, que é convertida em produtos comercializáveis através de tecnologias sustentáveis e de baixo impacto ambiental, em alternativa aos derivados de petróleo. ${ }^{1} \mathrm{~A}$ biomassa, sendo disponível em larga quantidade e renovável, merece presentemente muita e diversificada atenção como matéria-prima para a indústria química. ${ }^{1-6}$

O termo bioindústria engloba as instalações da indústria química que usam biomassa como matéria-prima, havendo presentemente muito interesse em desenvolver e implementar um conceito mais amplo, de natureza sistémica, o de biorrefinaria. A biorrefinaria, analogamente a uma refinaria de petróleo que inclua instalações de indústria petroquímica, que produz vários combustíveis e substâncias a partir do petróleo, é um agrupamento de instalações de processos de conversão de biomassa em biocombustíveis, produtos químicos e energia, permitindo um maior aproveitamento da biomassa. ${ }^{1,7} \mathrm{Um}$ exemplo de biorrefinaria é a produção de bioetanol, que pode ser usado quer como combustível, quer como reagente de base ("platform") no fabrico de outros produtos químicos. ${ }^{1,3}$ Atualmente, procura-se desenvolver biorrefinarias que utilizem a biomassa nos resíduos produzidos na cadeia de fornecimento de alimentos como matéria-prima,

*e-mail: gribeiro@fc.up.pt para minimizar a competição com a indústria alimentar pela biomassa virgem. ${ }^{7}$ Um exemplo refere-se à biomassa das cascas dos citrinos, resíduos resultantes do processamento de laranjas para a produção de sumos, que apresenta elevado potencial para o desenvolvimento de biorefinarias. ${ }^{8-10}$

Entre os produtos químicos que se podem obter da biomassa, são importantes os óleos essenciais, amplamente utilizados em vários domínios da atividade industrial. Por exemplo, devido às suas características em nível sensorial, mas também pela sua ação antibacteriana e fungicida, são usados nas indústrias da cosmética, perfumaria, alimentar e farmacêutica. ${ }^{11-14}$ Os resíduos resultantes do processamento de laranjas permitem a obtenção de um óleo essencial e do seu principal componente, R-(+)-limoneno (a seguir designado, mais simplesmente, por limoneno), bem como de outros produtos, nomeadamente bioetanol e nanocelulose..$^{15}$ Os citrinos representam um importante papel na indústria alimentar, principalmente na produção de sumos. Mundialmente, estima-se que a produção de citrinos ronde os 94,8 milhões de toneladas por ano, sendo o Brasil o líder mundial. A nível global, estima-se que 31,2 milhões de toneladas de citrinos são processadas industrialmente por ano, produzindo 15,6 milhões de toneladas de resíduos. ${ }^{1}$ Os principais componentes dos resíduos húmidos das cascas de citrinos são água ( $80 \%$ em peso), açucares, celulose e hemicelulose, pectina e limoneno. ${ }^{1}$ Os óleos essenciais dos citrinos são removidos das cascas antes de estas serem depositadas no ambiente, destacando-se o óleo de laranja. ${ }^{1,15,16}$

As principais utilizações do óleo de laranja são a aromatização de bebidas e produtos de confeitaria, a utilização como fragrância em perfumes, sabonetes e produtos para o lar, e a sua purificação para obtenção do seu principal componente com elevado grau de pureza, o limoneno. Este, presente em percentagem entre 90 e $95 \%$, é usado em larga escala em variadas aplicações: ${ }^{17-19}$ como reagente de base da indústria química para a síntese de compostos com estruturas semelhantes como, por exemplo, carveol, carvona, $\alpha$-terpineol, álcool perílico e ácido perílico ${ }^{1}$ no fabrico de borracha e tintas, e como agente 
dispersante para óleos, ${ }^{20}$ componente de óleos essenciais artificiais ${ }^{21}$ e solvente para resinas. ${ }^{20}$ Estudos recentes exploraram a produção de poliamidas e poliuretanos renováveis a partir do limoneno. ${ }^{22}$ No entanto, a maior utilização do limoneno, que tem incentivado o crescimento da sua extração, é como agente de limpeza, tanto em nível industrial como doméstico, uma vez que é ambientalmente seguro e mais eficaz que as os agentes de limpeza tradicionais. Assim, além de usado na produção de produtos de limpeza domésticos, é empregado como agente de limpeza nas indústrias petrolífera, automóvel, de pavimentação e eletrónica. ${ }^{23} \mathrm{O}$ limoneno tem um forte poder inseticida sendo, por isso, também bastante usado no fabrico de produtos com essa função. ${ }^{24-26}$ Como solvente, devido à sua baixa toxicidade, o limoneno pode substituir uma grande variedade de substâncias como, por exemplo, aguarrás mineral ("white spirits"), butanona, tolueno, xileno, éteres de glicol e solventes orgânicos clorados e fluorados, tal como os CFC's, cujo uso foi proibido. ${ }^{18} \mathrm{O}$ limoneno tem também aplicações na indústria farmacêutica, não só como solvente na síntese de compostos químicos, mas também como princípio ativo, uma vez que exibe baixa toxicidade para a saúde humana. É um solvente do colesterol e, como tal, tem sido utilizado na dissolução de cálculos biliares contendo colesterol, bem como na neutralização da azia (ácido gástrico); e exibe também atividade quimopreventiva contra vários tipos de cancro. ${ }^{27-29}$

O elevado valor comercial do óleo de laranja (e do limoneno, seu principal componente) devido à ampla aplicação industrial e ao interesse da utilização de biomassa como matéria-prima renovável, sugerem que o estudo comparativo dos processos da sua extração das cascas de laranja será interessante no contexto do ensino da Química Verde $(\mathrm{QV}){ }^{30,31}$ parecendo especialmente adequado para a prática de métricas de avaliação da verdura química, dada a variedade de técnicas alternativas usadas. As três principais técnicas de extração industrial das fragrâncias naturais e óleos essenciais são: (i) destilação por arrastamento de vapor, técnica que consiste na utilização do vapor de água para destilar os componentes do óleo essencial a uma temperatura inferior a $100{ }^{\circ} \mathrm{C}$ (após a condensação da fase de vapor, o óleo separa-se da fase aquosa, uma vez que são imiscíveis, o que facilita a sua remoção); (ii) separação mecânica, em que o óleo é removido da casca por processos mecânicos como prensagem, raspagem ou perfuração da casca; e (iii) extração com solventes, que consiste na extração das fragrâncias voláteis dos materiais naturais utilizando solventes não polares, e.g. tolueno, hexano e éter de petróleo. ${ }^{21} \mathrm{O}$ óleo de laranja é obtido industrialmente por extração mecânica da casca de laranja, sendo a prensagem das cascas para a extração do óleo frequentemente combinada com a produção de sumo.

Uma revisão bibliográfica na literatura educacional sobre os processos de extração do óleo de laranja/limoneno usados em aulas laboratoriais ${ }^{32-36}$ para obtenção do óleo e sua caracterização, no contexto do isolamento de produtos naturais, mostrou que, para além da utilização das técnicas clássicas de hidrodestilação ou destilação por arrastamento de vapor e extração com solvente, foram propostos outros processos: extração a microescala; ${ }^{37}$ extração do limoneno no contexto da síntese de outros produtos (e.g. (-)-carvona ${ }^{38}$ e $\alpha$-terpineol ${ }^{39}$ ), que o usam como reagente estequiométrico; bem como, no contexto da $\mathrm{QV}$, isolamento do limoneno utilizando dióxido de carbono líquido como solvente, para ser utilizado no laboratório de química analítica. ${ }^{40}$ Por outro lado, na revista Green Chemistry foram publicadas propostas de novos procedimentos de extração do óleo de laranja: o uso de líquidos iónicos como solventes de extração: ${ }^{11}$ a utilização de solventes mais benignos na extração, como o dióxido de carbono líquido, ${ }^{41}$ óleo alimentar e polímeros (polietilenoglicol e polipropilenoglicol) $;{ }^{42}$ e o uso de processos hidrotérmicos com micro-ondas de baixa temperatura. ${ }^{7}$ Estes estudos mostram preocupação em obter processos mais verdes para a extração do óleo de laranja, ${ }^{11,40-42}$ mas não incluem qualquer referência à importância da avaliação e análise da verdura dos processos tradicionais e alternativos.

O Brasil lidera mundialmente a produção de laranjas e de suco de laranja $\mathrm{a}^{1,16} \mathrm{e}$ é um grande produtor de óleos essenciais, nomeadamente de óleos de citrinos. Neste contexto, faz sentido incluir a extração do óleo de laranja e sua purificação nos programas das disciplinas experimentais de Química no Brasil. ${ }^{39}$ Por outro lado, o estudo laboratorial dos diversos processos tradicionais de extração do óleo de laranja permite promover a introdução da QV nos laboratórios de ensino pré-universitários e universitários, mediante a análise da verdura química com diversos tipos de métricas. Assim sendo, é aliciante tratar este tema em contexto educacional com vista a contribuir para o desenvolvimento de competências verdes dos alunos, cada vez mais importantes para o seu futuro profissional, ${ }^{43,44}$ no quadro presente em que se procura promover um desenvolvimento mais sustentável. Por estas razões, o presente trabalho teve como objetivo global investigar a verdura dos processos vigentes de extração do óleo de laranja, tendo em vista a sua aplicação no laboratório educacional.

Em suma, mais concretamente, os objetivos específicos deste trabalho foram: 1) avaliar a verdura química de diferentes protocolos publicados para extração do óleo de laranja, com vista a identificar quais são os processos tradicionais mais verdes; e 2) investigar a sua otimização, utilizando intensivamente métricas de verdura tradicionais, bem como outras de "inspiração industrial", para realizar uma avaliação multidimensional da verdura.

\section{METODOLOGIA}

O trabalho desenvolveu-se em cinco etapas, apresentadas a seguir (ver a Figura 1).

\section{Etapa I - Pesquisa bibliográfica}

A pesquisa bibliográfica de protocolos experimentais referentes à extração do óleo essencial de laranja e/ou do limoneno a partir da casca de laranja foi realizada no Journal of Chemical Education, na Química Nova e em livros de experiências de Química Orgânica. Os protocolos encontrados foram de dois tipos: os que partiam das cascas de laranja como matéria-prima, que utilizavam dois processos de extração diferentes, destilação por arrastamento de vapor (Figura 2, Processo 1, seis protocolos) ${ }^{26,32,34,38,39,45,46}$ e extração com solvente orgânico a frio (Figura 2, Processo 2, três protocolos). ${ }^{33,46,47}$ Por outro lado, foram encontrados protocolos que faziam apenas a purificação de óleo de laranja comercial para obtenção do limoneno (Figura 2, Processo 3 , dois protocolos). ${ }^{48}$

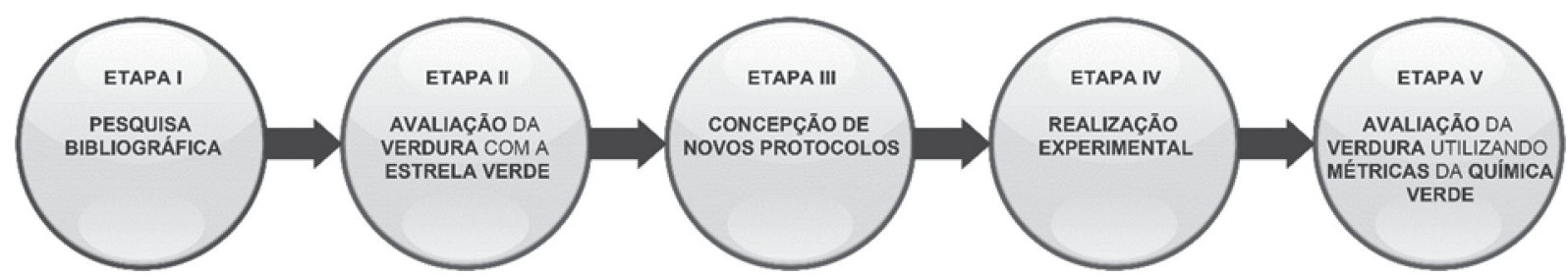

Figura 1. Metodologia seguida no trabalho 


\section{Etapa II - Avaliação da verdura dos protocolos da literatura com a métrica estrela verde}

Os protocolos referentes aos Processos 1 e 2 foram analisados considerando separadamente três fases: (i) extração do óleo essencial - remoção deste da casca das laranjas; (ii) isolamento - separação do óleo da água e/ou dos solventes utilizados; e (iii) purificação (quando incluída) - obtenção do limoneno com pureza aumentada. No caso dos protocolos que partem do óleo de laranja comercial só existe esta última fase. Mais informação sobre as diversas fases é fornecida na Parte experimental.

Para todos os protocolos de cada processo foi efetuada a análise da verdura do processo global e de cada fase. Esta avaliação individualizada das fases, realizada com a métrica holística estrela verde $(\mathrm{EV})^{49-51}$ (ver a secção Métricas), teve como objetivo esclarecer a forma como cada fase afeta a verdura global.
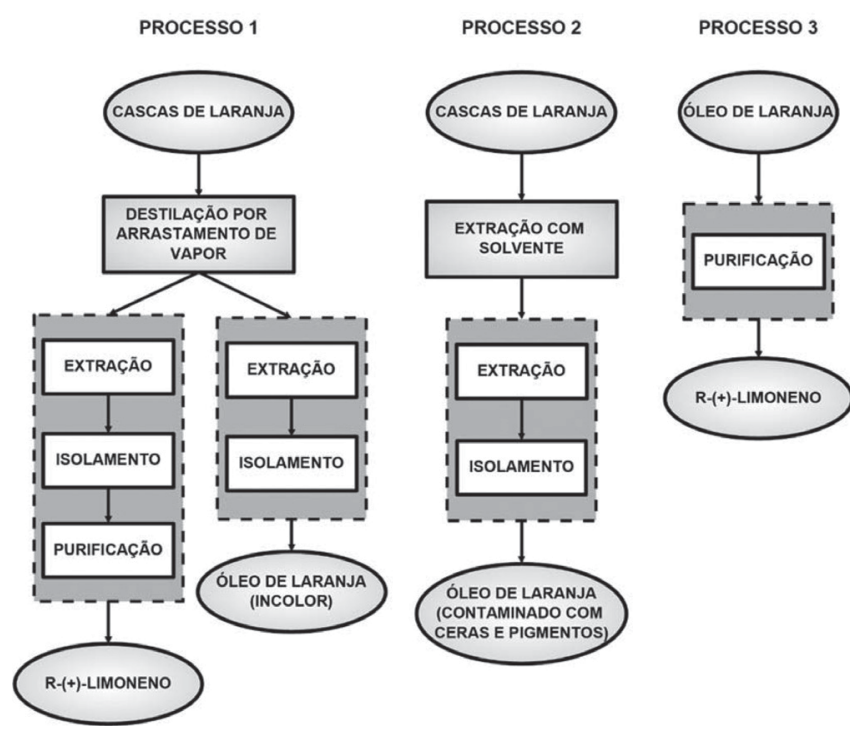

Figura 2. Esquema resumo dos diferentes tipos de processos nos protocolos da bibliografia (os retângulos representam operações; as elipses, materiais; os retângulos a tracejado, envolvem as fases de cada um dos processos)

\section{Etapa III - Conceção de novos protocolos}

Após a análise da verdura, verificou-se que todos os protocolos do processo 2 apresentavam uma verdura muito limitada, pelo que se optou por desenhar novos protocolos e testar novos solventes na extração do óleo de laranja para tentar melhorar a verdura.

\section{Etapa IV - Realização experimental dos protocolos selecionados}

Nesta etapa realizou-se experimentalmente a extração do óleo de laranja utilizando o protocolo avaliado como o mais verde para o processo 1, bem como os protocolos desenhados no trabalho para aumentar a verdura do processo 2. Para o processo 3 selecionou-se o protocolo mais verde, purificando-se uma amostra de óleo de laranja comercial (Sigma-Aldrich, ref. W282537), a seguir designada, para simplificar, por amostra comercial.

\section{Etapa V - Avaliação da verdura utilizando métricas da Química Verde}

Nesta etapa procedeu-se a avaliação da verdura dos protocolos realizados experimentalmente utilizando não só a $\mathrm{EV}$, mas também métricas quantitativas de massa, energia e tempo, descritas a seguir.

\section{MÉTRICAS}

As métricas usadas são apresentadas na Tabela 1, na qual se incluem as expressões para o seu cálculo.

Tabela 1. Métricas utilizadas na avaliação do trabalho experimental

Eficiência Material de Biomassa
BME $=100 \frac{\text { massa de óleo de laranja }}{\text { massa de casca de laranja }}$
Fator Ambiental (fator E) $\mathrm{E}=\frac{\text { massa de resíduos }}{\text { massa de óleo de laranja }}$
Throughput $=\frac{\text { massa de óleo de laranja }}{\text { tempo total }}$
Intensidade de Tempo (TI)
TI $=\frac{\text { tempo total }}{\text { massa de óleo de laranja }}$
Intensidade de Energia (EI)
energia total $=\frac{\text { massa de óleo de laranja }}{}$

A literatura tem usado ${ }^{11,12,21,37} \mathrm{o}$ termo rendimento para indicar a percentagem de bioproduto útil extraído da biomassa (neste caso percentagem em peso de óleo essencial extraído de um material natural), mas este rendimento não coincide com a definição de rendimento tradicional para as reações químicas. Recentemente, foi proposto o termo eficiência material (ME, do inglês "Material Efficiency") para designar a referida grandeza em estudos da extração de produtos químicos da biomassa, ${ }^{52,53}$ mas aqui propôe-se o termo eficiência material de biomassa (BME, do inglês "Biomass Material Eficiency") para explicitar a particularidade de a eficiência material se referir à biomassa. Quando vários produtos são extraídos da biomassa em paralelo, a grandeza é definida para o seu conjunto, isto é, dividindo a massa total dos produtos úteis extraídos pela massa de biomassa de partida.

O fator E é uma métrica da quantidade de resíduos produzidos, definida como a razão entre a massa total de resíduos e a massa de produto obtido (o seu valor ideal é zero, que ocorre se não houver produção de quaisquer resíduos). ${ }^{52,54} \mathrm{~A}$ água é geralmente ignorada neste cálculo, o que foi seguido neste trabalho. O fator E, sendo uma métrica normalizada pelo produto, pode ser expresso como uma soma de parcelas referentes aos diversos tipos de resíduos. ${ }^{55}$ No caso presente, haverá uma parcela, o fator $\mathrm{E}_{\mathrm{BIO}}$, referente a resíduos de biomassa, e outra, o fator $\mathrm{E}_{\mathrm{NBIO}}$, referente aos outros resíduos, sendo fator $\mathrm{E}=$ fator $\mathrm{E}_{\mathrm{BIO}}+$ fator $\mathrm{E}_{\mathrm{NBIO}}$. A métrica $\mathrm{BME}$ está relacionada com a métrica parcial de quantidade de resíduos provenientes da biomassa, sendo $\mathrm{BME}=1 /\left(\right.$ Fator $\left.\mathrm{E}_{\mathrm{BIO}}+1\right)$. Esta expressão é útil para verificar a correção dos valores calculados para as duas métricas (ver Tabelas 6S, 8S e 10S do Material Suplementar).

As métricas intensidade de energia (EI), intensidade de tempo (TI) e "throughput" ${ }^{56}$ (ou "velocidade" de produção, melhor taxa de produção, a quantidade de massa de produto obtido por unidade de tempo) são métricas de utilização industrial, habitualmente ausentes no ensino, mas foram usadas neste trabalho para trazerem para o contexto educacional questões centrais como a utilização de energia 
e a importância que a duração dos processos têm do ponto de vista da economia do processo industrial, devido à sua influência nos custos de produção. Assim, é importante chamar a atenção dos estudantes para essas variáveis. EI é a razão entre a energia utilizada e a massa do produto obtido e TI a razão entre o tempo utilizado e esta mesma massa. Como na indústria se procura maximizar a velocidade de obtenção do produto (throughput), um dos fatores mais importantes para o custo de produção, ${ }^{57,58}$ para o seu cálculo exige-se o conhecimento do tempo das operações. Para permitir a obtenção destas métricas, as experiências incluíram a medição das energias e tempos ao longo dos procedimentos laboratoriais.

Para a avaliação da verdura química utilizou-se a métrica EV, ${ }^{49-51}$ construída com base nos perigos das substâncias envolvidas, mais precisamente a sua versão revista ${ }^{51}$ que utiliza as frases de perigo do Sistema Global Harmonizado de Classificação e Rotulagem de Químicos. ${ }^{59} \mathrm{~A}$ EV é uma métrica holística da verdura química, de natureza gráfica, que cobre todos os princípios da QV aplicáveis em cada situação sob estudo (experiência, operação, síntese, etc.), permitindo comparações visuais fáceis da verdura. Desde que os procedimentos sejam descritos com suficiente detalhe na literatura, a EV não exige a sua realização laboratorial prévia para avaliar a verdura química e por isso é útil, quando há várias alternativas, para a seleção do procedimento mais verde para posterior realização experimental.

\section{PARTE EXPERIMENTAL}

\section{Avaliação da verdura dos protocolos de literatura}

Os protocolos encontrados na literatura são resumidos na Tabela 2. As EV construídas para todos os protocolos são apresentadas na Figura 2S do Material Suplementar; no "Catálogo digital de verdura de atividades laboratoriais para o ensino da Química Verde" ${ }^{\prime 60}$ proporciona-se informação detalhada sobre a realização da avaliação, que inclui a construção das EV para as diferentes fases integrantes de cada protocolo (extração, isolamento e purificação), bem como para o processo global. Na Tabela 2, para cada protocolo, são indicadas duas referências: a primeira refere-se à peça bibliográfica onde foi obtido o protocolo avaliado e a segunda à página da net do referido Catálogo ${ }^{60} \mathrm{em}$ que descreve a avaliação da verdura com a EV e onde se pode consultar detalhes (descrição do protocolo, EV para cada fase e global, bem como as tabelas de apoio à sua construção).

Os resultados globais da avaliação dos protocolos com a EV (traduzidos pelo Índice de Preenchimento da Estrela, IPE) ${ }^{51}$ usados a seguir na seleção de protocolos, apresentam-se na Tabela 3.

\section{Processo 1 - Destilação por arrastamento de vapor}

A partir da análise das EV dos seis protocolos encontrados na literatura para este processo verificou-se que o protocolo mais verde é o $D^{26,64}$ (ver a Tabela 3 e Figura $2 \mathrm{~S}$ do Material Suplementar). A verdura da fase de extração é igual e elevada para todos os protocolos avaliados (IPE $=83,3$ ), uma vez que a operação de extração é sempre a mesma. No caso do isolamento, a verdura varia entre IPE=8,3 (Protocolo B, ${ }^{32,62}$ Tabela 2) e IPE=66,7 (Protocolo $\mathrm{D}^{26}$ ). Como a pontuação de cada um dos princípios nas EV globais corresponde à menor pontuação no conjunto das EV de extração e isolamento (e no caso do protocolo E, ${ }^{45,65}$ Tabela 2, também de purificação), a fase com menor verdura química será a determinante da verdura global. O protocolo $\mathrm{D}$, com maior verdura na fase de isolamento, apresenta a maior verdura global e foi o selecionado para a realização experimental (ver a Figura 3, que apresenta as EV obtidas para os protocolos selecionados para execução laboratorial, permitindo a comparação das respetivas verduras).
Tabela 2. Resumo dos protocolos recolhidos na literatura para os três processos PROCESSO 1 - DESTILAÇÃO POR ARRASTAMENTO DE VAPOR Matéria-prima - Cascas de laranja

Extração do óleo essencial - Destilação por arrastamento de vapor (água)

\begin{tabular}{|c|c|}
\hline \multicolumn{2}{|c|}{ Protocolo $\mathrm{A}^{38,61}$} \\
\hline Isolamento & $\begin{array}{l}\text { Extração líquido-líquido (diclorometano e sulfato de sódio } \\
\text { anidro) com evaporação do solvente }\end{array}$ \\
\hline Purificação & Não indicada \\
\hline \multicolumn{2}{|c|}{ Protocolo B ${ }^{32,62}$} \\
\hline Isolamento & $\begin{array}{l}\text { Extração líquido-líquido (diclorometano e sulfato de sódio } \\
\text { anidro) com evaporação do solvente a pressão reduzida }\end{array}$ \\
\hline Purificação & Não indicada \\
\hline \multicolumn{2}{|c|}{ Protocolo C C $^{34,63}$} \\
\hline Isolamento & $\begin{array}{l}\text { Extração líquido-líquido (diclorometano e sulfato de } \\
\text { magnésio anidro) }\end{array}$ \\
\hline Purificação & Não indicada \\
\hline \multicolumn{2}{|c|}{ Protocolo D $\mathbf{D}^{26,64}$} \\
\hline Isolamento & $\begin{array}{l}\text { Extração líquido-líquido (sem solvente e sulfato de } \\
\text { cálcio anidro) }\end{array}$ \\
\hline Purificação & Não indicada \\
\hline \multicolumn{2}{|c|}{ Protocolo E $\mathbf{E}^{45,65}$} \\
\hline Isolamento & $\begin{array}{l}\text { Extração líquido-líquido (pentano e sulfato de magnésio } \\
\text { anidro) }\end{array}$ \\
\hline Purificação & Destilação fracionada a pressão reduzida \\
\hline \multicolumn{2}{|c|}{ Protocolo $F^{46,66}$} \\
\hline Isolamento & $\begin{array}{l}\text { Extração líquido-líquido (éter de petróleo e sulfato de } \\
\text { sódio anidro) }\end{array}$ \\
\hline Purificação & Não indicada \\
\hline
\end{tabular}

PROCESSO 2 - EXTRAÇÃO COM SOLVENTE

Matéria-prima - Cascas de laranja

Extração do óleo essencial - Extração com solventes

Protocolo G ${ }^{33,67}$

Extração Imersão da matéria-prima em éter de petróleo durante $48 \mathrm{~h}$

Isolamento Destilação para remoção do solvente e secagem com sulfato de sódio anidro

\begin{tabular}{ll}
\hline Purificação & Não indicada \\
\hline Protocolo $\mathbf{H}^{47,68}$ & \\
\hline Extração & $\begin{array}{l}\text { Imersão sucessiva da matéria-prima em três porções de } \\
\text { pentano durante } 10 \mathrm{~min} .\end{array}$
\end{tabular}

Isolamento Secagem com sulfato de sódio anidro e remoção de solvente a baixa temperatura em atmosfera de azoto

\begin{tabular}{ll}
\hline Purificação & Não indicada \\
\hline Protocolo I ${ }^{46,69}$ & \\
\hline Extração & $\begin{array}{l}\text { Imersão sucessiva da matéria-prima triturada em três } \\
\text { porções de éter de petróleo }\end{array}$
\end{tabular}

Isolamento Secagem com sulfato de sódio anidro e remoção de solvente à temperatura ambiente

Purificação Não indicada

PROCESSO 3 - PURIFICAÇÃO DO ÓLEO DE LARANJA

Matéria-prima - Óleo de laranja

Protocolo J $\mathbf{J}^{48,70}$

Purificação Destilação por arrastamento de vapor do óleo seguida de extração com éter de petróleo; secagem com sulfato de magnésio anidro; destilação fracionada a pressão reduzida

Protocolo $\mathbf{K}^{48,71}$

Purificação Destilação fracionada do óleo de laranja a pressão reduzida

* Como são imiscíveis, o óleo e a água são separados simplesmente por decantação sem a utilização de qualquer solvente. 
Tabela 3. Valores dos IPE das EV globais para os protocolos de literatura

\begin{tabular}{lcc}
\hline PROCESSO & PROTOCOLO & IPE \\
\hline \multirow{4}{*}{ P1 } & A & 16,7 \\
& B & 8,3 \\
& C & 16,7 \\
& D & 58,3 \\
& E & 8,3 \\
\hline & F & 16,7 \\
P2 & G & 16,7 \\
& H & 16,7 \\
\hline \multirow{2}{*}{ P3 } & I & 25,0 \\
\hline
\end{tabular}

Processo 2 - Extração com um solvente orgânico

A avaliação global dos três protocolos da literatura $(\mathrm{G}, \mathrm{H}$ e I, Tabela 2) indicou como mais verde o protocolo I ${ }^{46,69}$ (ver a Tabela 3 e Figura $2 \mathrm{~S}$ do material suplementar); a verdura da fase de extração é igual para todos os protocolos avaliados $(\mathrm{IPE}=25,0)$, mas na fase de isolamento o protocolo I apresenta a maior verdura pelo fato de o isolamento ocorrer à temperatura ambiente $($ IPE $=41,7)$. Nenhum destes protocolos foi selecionado para realização experimental atendendo a que os solventes utilizados na extração, o éter de petróleo e o pentano, envolvem variados perigos para a saúde humana (ver adiante). Por isso, para implementação laboratorial, foram concebidos outros protocolos com solventes mais benignos, que serão apresentados na secção seguinte.

\section{Processo 3 - Purificação do óleo de laranja}

A avaliação dos protocolos $\mathrm{J}^{48.70} \mathrm{e} \mathrm{K}^{48,71}$ (Tabela 2) mostra que o protocolo $\mathrm{K}^{48,71}$ (ver a Tabela 3 e a Figura $2 \mathrm{~S}$ do Material Suplementar)

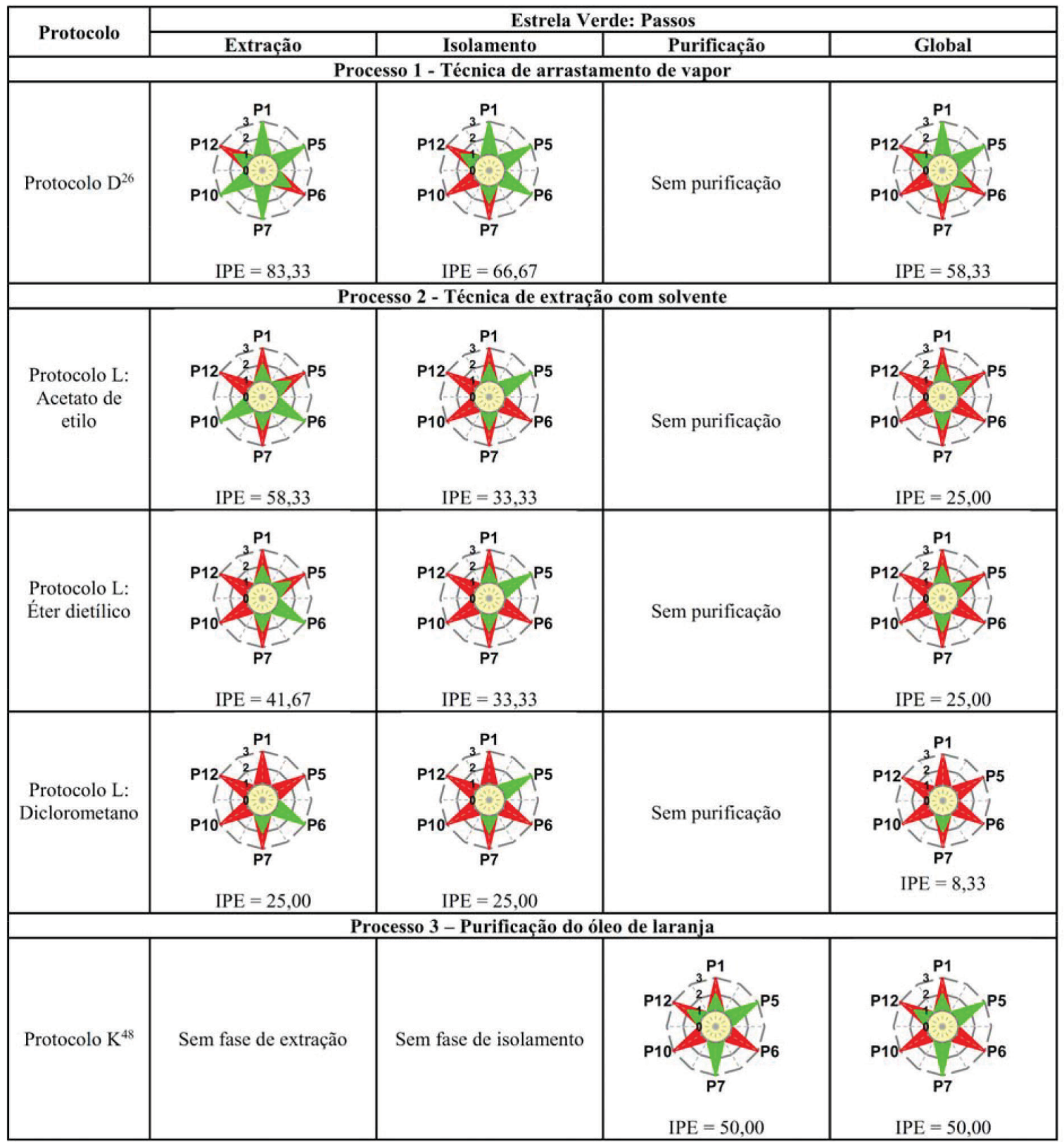

Figura 3. Comparação entre as EV dos protocolos escolhidos para realização experimental para cada processo; os protocolos L foram desenvolvidos neste trabalho, ver texto 
apresenta a maior verdura química, sendo respetivamente IPE $=50,0$ e IPE $=16,7$ para as EV dos dois protocolos. Assim, foi selecionado para realização experimental o protocolo K (Figura 3).

\section{Conceção de novos protocolos para a extração com solvente orgânico}

Para este processo, em alternativa aos solventes orgânicos referidos nos protocolos de literatura, procuraram-se outros com características semelhantes que pudessem substituí-los: acetato de etilo (AcEt), éter dietílico $\left(\mathrm{Et}_{2} \mathrm{O}\right)$ e diclorometano (DCM), este último usado nos protocolos A, B e C. Na Tabela 4 apresentam-se os perigos dos solventes, quer dos usados nos protocolos, quer dos substituintes considerados para serem usados na extração.

Tabela 4. Frases de perigo para os solventes envolvidos no estudo

\begin{tabular}{ll}
\hline Solvente & \multicolumn{1}{c}{ Frases de perigo } \\
\hline \multirow{3}{*}{ Acetato de etilo } & H225 - Líquido e vapor facilmente inflamáveis \\
AcEt & H336 - Provoca irritação ocular grave \\
& $\begin{array}{l}\text { EUH066 - Pode provocar sonolência ou vertigens } \\
\text { exposição repetida }\end{array}$ \\
\hline
\end{tabular}

H315 - Provoca irritação cutânea

H319 - Provoca irritação ocular grave

H335 - Pode provocar irritação das vias respiratórias

Diclorometano H336 - Pode provocar sonolência ou vertigens

DCM

H351 - Suspeito de provocar cancro

H373 - Pode afetar os órgãos após exposição prolongada ou repetida

H224 - Líquido e vapor extremamente inflamáveis H304 - Pode ser mortal por ingestão e penetração nas vias respiratórias

H315 - Provoca irritação cutânea

Éter de petróleo H336 - Pode provocar sonolência ou vertigens

H361 - Suspeito de afetar a fertilidade

H373 - Pode afetar os órgãos após exposição prolonga-

da ou repetida por inalação

H411 - Tóxico para os organismos aquáticos com efeitos duradouros

H224 - Líquido e vapor extremamente inflamáveis

H302 - Nocivo por ingestão

Éter dietílico H336 - Pode provocar sonolência ou vertigens

$\mathrm{Et}_{2} \mathrm{O} \quad$ EUH019 - Pode formar peróxidos explosivos

EUH066 - Pode provocar pele seca ou gretada, por exposição repetida

H225 - Líquido e vapor facilmente inflamáveis

H304 - Pode ser mortal por ingestão e penetração nas vias respiratórias

Pentano H336 - Pode provocar sonolência ou vertigens H411 - Tóxico para os organismos aquáticos com efeitos duradouros

EUH066 - Pode provocar pele seca ou gretada, por exposição repetida

Como solventes de substituição para a fase de isolamento foram escolhidos o AcEt e o $\mathrm{Et}_{2} \mathrm{O}$, por apresentarem menor potencial de risco para a saúde humana (Tabela 4). Como estes solventes não são usados em nenhum protocolo de literatura de extração do limoneno, utilizou-se ainda o DCM, sugerido nos protocolos A-C do processo 1 (Tabela 2) como solvente adequado para o limoneno. Embora este solvente apresente também perigos elevados para a saúde (Tabela 4), foi usado para se avaliar comparativamente com os referidos acima. O procedimento da fase de extração dos novos protocolos (L), resumido na Tabela 5 (ver detalhes na secção 3.2.2.1 do Material Suplementar), é similar ao dos protocolos I, ${ }^{46,69}$ Tabela 2, constituído por imersão sucessiva do epicarpo das cascas de laranja em duas porções de $100 \mathrm{~mL}$ do solvente escolhido (AcEt, $\mathrm{Et}_{2} \mathrm{O}$ ou DCM), mas o isolamento é realizado por evaporação do solvente, num evaporador rotativo a pressão reduzida, o que prejudica a pontuação da EV para o sexto princípio relativamente aos protocolos indicados na literatura, mas evita contaminar a atmosfera com os solventes.

Tabela 5. Resumo dos protocolos L

\begin{tabular}{ll}
\hline Protocolos L & \\
\hline Matéria-prima & Cascas de laranja \\
\hline Extração do óleo essencial & $\begin{array}{l}\text { Imersão sucessiva da matéria-prima em } \\
\text { duas porções de } 100 \mathrm{~mL} \text { de solvente } \\
\text { (acetato de etilo, éter dietílico ou di- } \\
\text { clorometano) durante } 10 \text { min }\end{array}$ \\
\hline Isolamento & $\begin{array}{l}\text { Secagem com sulfato de sódio anidro } \\
\text { e remoção de solvente no evaporador } \\
\text { rotativo a baixa temperatura e pressão } \\
\text { reduzida }\end{array}$ \\
\hline Purificação & $\begin{array}{l}\text { Destilação fracionada a pressão re- } \\
\text { duzida }\end{array}$ \\
\hline
\end{tabular}

\section{Realização experimental de protocolos}

Os protocolos listados na Figura 3, selecionados da literatura mediante avaliação preliminar da verdura com a EV ou concebidos a partir destes com vista a melhorar a verdura, foram realizados experimentalmente, conforme descrito sucintamente a seguir (ver detalhes na secção 3 do Material Suplementar). O trabalho experimental envolveu medições não habituais nos laboratórios educacionais, como medições do tempo gasto nas operações e da energia utilizada.

\section{Processo 1 - Destilação por arrastamento de vapor}

Ao longo do trabalho experimental baseado no protocolo $\mathrm{D}^{26}$ foram introduzidas alterações em nível da escala, montagem ou parte da casca de laranja utilizada, com o objetivo de obter maior quantidade de óleo de laranja no menor tempo possível. Na Figura 4 (parte de cima, Processo 1) apresenta-se o roadmap que sintetiza as alterações introduzidas no protocolo D original, os seus objetivos e as melhorias que se foram obtendo. Destas sucessivas alterações resultaram quatro variantes de procedimento, D1-D4. No Material Suplementar, secção 3.2.1, apresentam-se descrições pormenorizadas dos procedimentos experimentais e da caracterização do limoneno obtido.

Na comparação do aspeto dos óleos de laranja obtidos pelo protocolo D4 com o da amostra comercial (Figura 5S, secção 3.2.1.2 do Material Suplementar), verificou-se que o óleo obtido era incolor e límpido, indicando ausência de qualquer tipo de pigmento corado ou cera, enquanto o comercial apresentava um tom amarelo pálido (sintoma de contaminação, possivelmente devida ao seu processo industrial de obtenção ser a prensagem a frio ${ }^{21}$ ).

$\mathrm{O}$ óleo de laranja obtido foi caracterizado por ${ }^{1} \mathrm{H}$ RMN e por cromatografia gasosa e comparado com o ${ }^{1} \mathrm{H}$ RMN obtido para a amostra comercial. A análise dos espectros de ${ }^{1} \mathrm{H}$ RMN (Figuras 6S e 7S, secção 3.2.1.2 do Material Suplementar) permitiu concluir que o óleo de laranja obtido, assim como o comercial, são compostos essencialmente por R-(+)-limoneno. Nenhum dos outros constituintes do óleo apresenta desvios significativos no espetro, confundindo-se mesmo com o ruido, indicando que estão presentes em pequenas quantidades, tal como esperado. A análise por cromatografia gasosa permitiu estimar que a percentagem de limoneno presente no óleo obtido e na amostra comercial ronda os $93 \%$ e $95 \%$, respetivamente, valores que se encontram entre os limites indicados na literatura, $90-95 \% .{ }^{21}$ 
PROCESSO 1 - Destilação por arrastamento de vapor
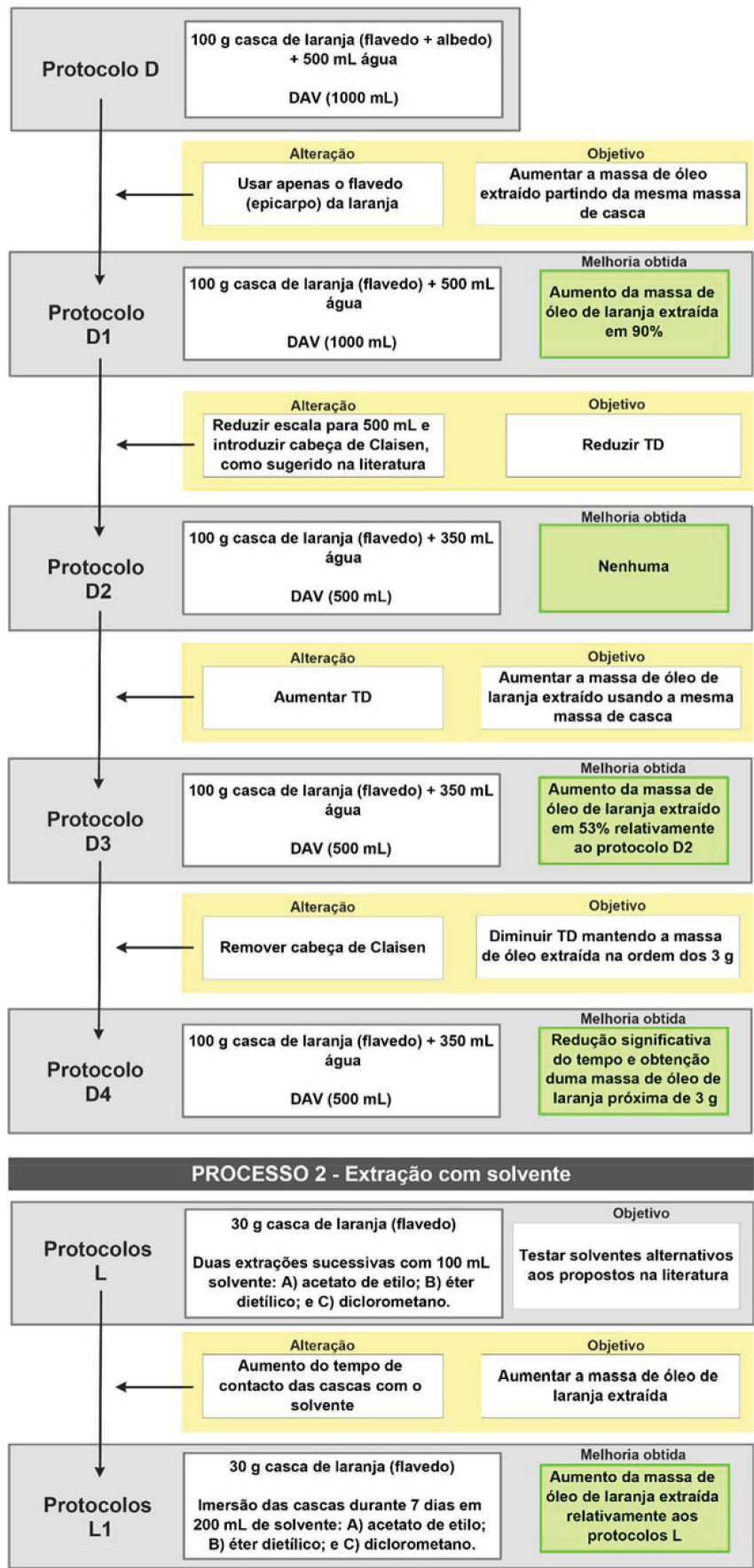

Figura 4. Roadmap que sintetiza o trabalho experimental realizado para os processos 1 e 2 ( DAV $(X \mathrm{~mL})$, destilação por arrastamento de vapor em balão de $X \mathrm{~mL} ; T D$, tempo de destilação)

Com o objetivo de aumentar quantidade de óleo obtida atendeu-se à morfologia da laranja, mais precisamente ao modo como o óleo essencial está distribuído no fruto. A laranja é constituída por três camadas, o flavedo ou epicarpo, o albedo ou mesocarpo e o endocarpo. A casca da laranja contém duas camadas: o epicarpo, camada rica em pigmentos onde estão contidas as glândulas de óleo, e o albedo, composto de células esponjosas de forma irregular e cor branca, separadas por grandes bolhas de ar. O óleo essencial está contido no interior de glândulas próprias (diâmetro de 0,4 a 0,6 mm), situadas imediatamente após a epiderme do fruto, no epicarpo, pelo que se aumenta a eficiência da operação se se fizer a extração a partir apenas do epicarpo da casca. Com esta base, introduziu-se uma alteração no protocolo D, utilizando apenas o epicarpo de cascas de laranja como matéria-prima (protocolo D1), que permitiu um aumento de $90 \%$ na massa de limoneno obtido, mantendo-se o odor e aspeto do produto.

Para se investigar se seria possível diminuir o tempo necessário à destilação por arrastamento de vapor, reduziu-se a escala do balão, de $1000 \mathrm{~mL}$ para $500 \mathrm{~mL}$, e introduziu-se uma cabeça de Claisen na montagem (protocolo D2). A redução da escala permitiu diminuir a quantidade de água usada. No entanto, verificou-se que a quantidade de destilado era aproximadamente metade da obtida nos casos anteriores no mesmo intervalo de tempo. Por isso, não foi possível interromper a destilação mais cedo, sendo necessário manter o mesmo tempo. A massa de óleo obtida foi semelhante à obtida no procedimento D1. Em face destes resultados, prolongou-se o tempo de destilação para obter uma quantidade de destilado semelhante à dos protocolos anteriores, D1 e D2 (protocolo D3). Verificou-se ser necessário mais de 5 horas para cumprir esse objetivo, tendo a massa de óleo obtida aumentado (53\%) relativamente ao protocolo D2.

Por fim, decidiu-se remover a cabeça de Claisen para investigar se, à escala de $500 \mathrm{~mL}$, se conseguia extrair uma massa de óleo da ordem dos $3 \mathrm{~g}$ em 3 1 1 2 horas em vez das mais de 5 horas necessárias no procedimento D3, objetivo que foi alcançado (protocolo D4). No entanto, experiências adicionais mostraram não ser possível diminuir mais o tempo de destilação, uma vez que a quantidade de óleo obtida diminuía bastante.

\section{Processo 2 - Extração com um solvente orgânico}

$\mathrm{O}$ trabalho experimental baseado nos protocolos L conduziu a resultados insatisfatórios com os três solventes alternativos (AcEt, $\mathrm{Et}_{2} \mathrm{O}$ e DCM), porque a quantidade de óleo extraída foi muito pequena. Assim, decidiu aumentar-se o tempo de contacto da matéria-prima com o solvente para sete dias (geralmente o tempo que decorre entre as aulas de laboratório), em vez das extrações sucessivas utilizadas nos protocolos L (protocolos L1). Na Figura 4 (parte inferior, Processo 2) apresenta-se o roadmap que sintetiza a alteração nos protocolos, bem como os resultados obtidos (descrições pormenorizadas dos procedimentos são incluídas no Material Suplementar, secção 3.2.2). Com os protocolos L1 consegue-se extrair óleo de laranja no caso dos três solventes testados, embora as quantidades variassem bastante de solvente para solvente, sendo o DCM o solvente mais eficiente em termos de quantidade de óleo extraída. Os resultados são apresentados e discutidos em pormenor na secção seguinte.

A comparação dos aspetos do óleo de laranja obtido por este processo, da amostra comercial e do óleo obtido por destilação por arrastamento de vapor, processo 1 (Figura 9S, secção 3.2.2.2 do Material Suplementar), mostrou que o óleo extraído com DCM apresenta um tom amarelo mais forte do que comercial, indicando uma maior contaminação por pigmentos. O respetivo espectro de ${ }^{1} \mathrm{H}$ RMN (Figura 10S, secção 3.2.2.2 do Material Suplementar) evidenciou que o óleo continha substâncias ausentes nas amostras comercial e no óleo obtido no processo 1, possivelmente pigmentos responsáveis pela coloração. Verificou-se ainda a presença de DCM, uma vez que é difícil extrair todo o DCM sem evaporar também óleo. Em suma, a qualidade do óleo essencial obtido por extração com DCM é inferior à obtida por destilação por arrastamento de vapor, provavelmente devido à contaminação.

\section{Processo 3 - Purificação do óleo de laranja}

A amostra comercial foi purificada seguindo o protocolo $\mathrm{K}$, com uma redução para microescala (balão de $10 \mathrm{~mL}$ ), mas o espectro de ${ }^{1} \mathrm{H}$ RMN do óleo purificado não mostrou alteração relativamente ao do óleo não purificado. No entanto a análise por cromatografia 
gasosa permitiu verificar que a percentagem de limoneno aumentou de $95 \%$ para $98 \%$ com a purificação. Na secção 3.2.3 do Material Suplementar incluem-se detalhes do procedimento, bem como uma imagem da montagem usada (Figura 11S) e os espetros de 1H RMN do óleo comercial (Figura 6S) e do limoneno obtido após purificação deste (Figura 12S).

\section{RESULTADOS E DISCUSSÃO}

\section{Avaliação com a Estrela Verde}

As EV dos protocolos de destilação por arrastamento de vapor e extração com solventes realizados experimentalmente (processos $1 \mathrm{e}$ 2 , respetivamente), apresentadas na Figura 3, mostram que o protocolo $\mathrm{D}$ (processo 1), que não requer solventes orgânicos, é o mais verde $(\mathrm{IPE}=58,3)$. Os protocolos $\mathrm{L}$, seguidos no processo 2, apresentam uma verdura mais baixa, que varia com o solvente usado no isolamento. Quando se usa AcEt ou $\mathrm{Et}_{2} \mathrm{O}$ a verdura é reduzida (IPE=25,0), mas com DCM é ainda mais reduzida (IPE $=8,3$ ). Por outro lado, o protocolo $\mathrm{K}$, relativo à purificação do óleo de laranja (processo 3), apresenta verdura $(\mathrm{IPE}=50,0)$ próxima da do protocolo $\mathrm{D}(\mathrm{IPE}=$ 58,3 ), porque não utiliza solventes, já que consiste numa destilação fracionada a pressão reduzida. Os protocolos D1-D4 apresentam a mesma $\mathrm{EV}$ que o protocolo $\mathrm{D}$ e os protocolos $\mathrm{L} 1$ (AcEt, $\mathrm{Et}_{2} \mathrm{O}, \mathrm{DCM}$ ) a mesma $\mathrm{EV}$ que os protocolos L correspondentes, pois as alterações introduzidas não afetam os parâmetros avaliados pela EV. O protocolo L com DCM apresenta menor verdura do que os protocolos da literatura porque, conforme já referido, o solvente é separado num evaporador rotativo à pressão reduzida, o que implica, porém, menor impacto sobre o ambiente. Esta situação exemplifica como as interações entre as diversas dimensões da verdura podem ser importantes, requerendo soluções de compromisso na otimização desta.

\section{Avaliação com métricas de massa}

Na Figura 5 apresentam-se os valores obtidos para as métricas fator E, BME e throughtput para todos os protocolos realizados (os dados experimentais usados nos cálculos constam das Tabelas $6 \mathrm{~S}$ e 8S, secção 3.2.1.3, e 10S, secção 3.2.2.3, do Material Suplementar).

No caso da destilação por arrastamento de vapor (processo 1), os valores da BME para os protocolos D1-D4 são cerca de duas a cinco vezes superiores, para o throughtput duas a quatro vezes superiores e para o fator E cerca de metade a um quinto inferiores aos obtidos para o protocolo D (Figura 5). Este facto deve-se ao uso, como matéria-prima, do epicarpo da casca de laranja em vez de toda a casca. Segundo a literatura, ${ }^{12,21}$ a percentagem de óleo essencial extraída de materiais naturais varia entre cerca de $0,01 \%$ e $5 \%$, dependendo do processo de isolamento e do material natural. Os valores obtidos para essa percentagem (aqui designada por BME) nos diferentes procedimentos do processo 1 variam de $0,61 \%$ a $3,04 \%$ (Tabela $6 \mathrm{~S}$ e 8S, no Material Suplementar, secção 3.2.1.3), portanto dentro do intervalo indicado.

Quanto ao fator E, o protocolo D apresenta o valor mais elevado (entre 74 e 170) de todos os protocolos do processo 1, por se ter usado como matéria-prima toda a casca de laranja e não apenas o epicarpo, como nos protocolos D1-D4, sendo a massa de limoneno obtida muito mais baixa. Como os procedimentos D e D1 foram realizados em balão de $1000 \mathrm{~mL}$, foi necessária uma maior quantidade de água relativamente aos procedimentos D2-D4, em que se utilizou um balão de $500 \mathrm{~mL}$, o que explica que o fator E para estes últimos seja inferior ao de D1.

Para o caso da extração com solventes (processo 2, protocolos L1), quando se usou DCM, como reportado na literatura, ${ }^{32,34,38}$ o valor

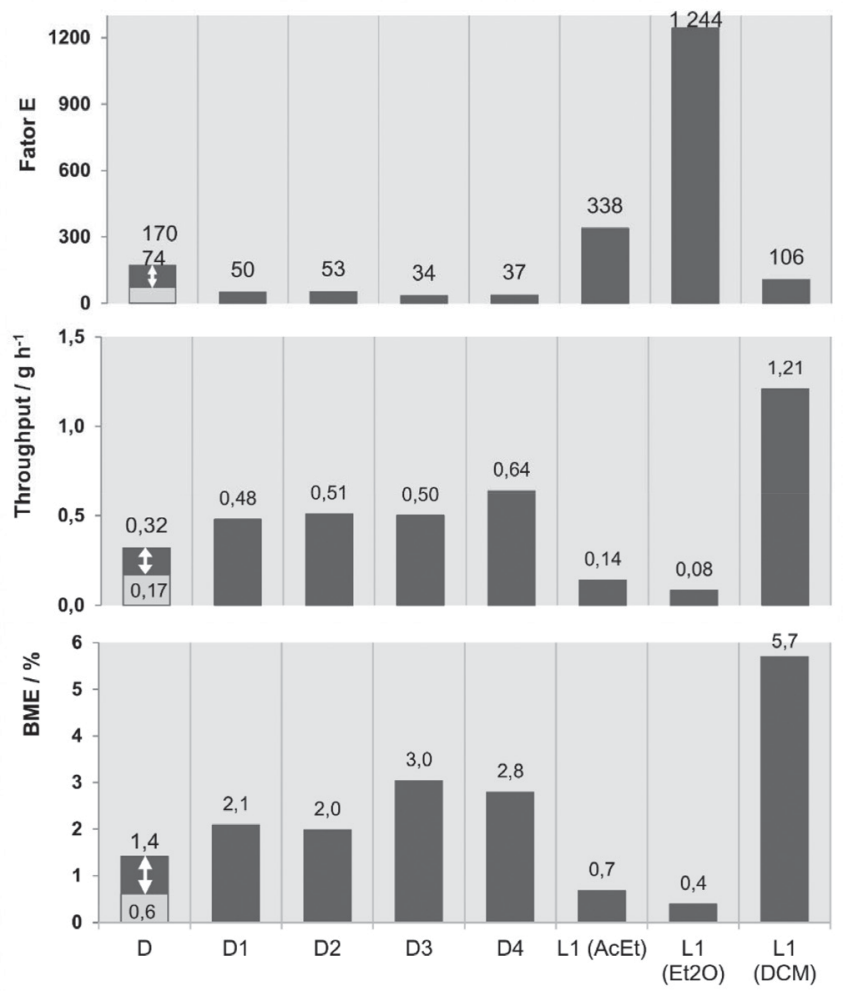

Figura 5. Valores de BME, throughtput e fator E para o processo 1 (destilação por arrastamento de vapor): D-D4; e processo 2 (extração com solventes): L1); para o protocolo D apresenta-se o intervalo de valores obtidos em quatro experiências ( $\downarrow)$

obtido para a BME foi $5,7 \%$, bastante superior ao encontrado para os outros dois solventes, $\mathrm{AcEt}$ ou $\mathrm{Et}_{2} \mathrm{O}, 0,7 \%$ e $0,4 \%$, respetivamente. Em consequência, a utilização destes solventes para a extração não parece viável, apesar de serem menos perigosos para a saúde humana.

Os solventes são recuperados após extração no evaporador rotativo e a massa de solvente recuperado não constitui um resíduo e, portanto, não é considerada no cálculo do fator E (ver a Figura 6 , onde se mostram os intervalos de valores das massas das substâcias em jogo). Se o solvente não fosse recuperado, os valores do fator E aumentavam (ver valores nas Tabelas 9S e 10S do Material Suplementar, secção 3.2.2.3). O volume de solvente recuperado variou com a volatilidade do solvente, constituindo $15,0 \%, 42,5 \%$ e $77,4 \%$ do volume/massa inicial, repetivamente para o $\mathrm{Et}_{2} \mathrm{O}, \mathrm{DCM}$ e AcEt. Quanto mais volátil o solvente, menor a massa recuperada, devido provavelmente a perdas para a atmosfera, o que revela dois problemas quanto à verdura: perdas de solvente para reutilização e contaminação da atmosfera. O AcEt, solvente menos volátil, permite obter a menor massa de resíduos (incluindo perdas por volatilização), já que se consegue recuperar a maior percentagem do solvente inicial. Por outro lado, o DCM conduz à maior massa de resíduos, embora a recuperação tenha sido superior à do $\mathrm{Et}_{2} \mathrm{O}$. Isto deve-se ao facto do DCM ter uma densidade bastante superior à do $\mathrm{Et}_{2} \mathrm{O}$, respetivamente $1,33 \mathrm{~g} \mathrm{~cm}^{-3}$ e $0,71 \mathrm{~g} \mathrm{~cm}^{-3}$. Como se usaram volumes iniciais de solvente iguais, e não massas, as diferentes densidades vão ter peso significativo nas massas de resíduos. Este caso mostra como a densidade dos solventes pode influenciar os valores do fator E, isto é, a verdura química - um aspeto que, tanto quanto os autores sabem, nunca foi discutido na literatura.

O protocolo L1 realizado com DCM é o que apresenta o menor valor de fator E, embora produza a maior massa de resíduos (Figura 6), porque a massa de óleo de laranja extraído foi muito superior. No entanto, os valores de throughput obtidos para este processo 
são muito baixos, devido ao elevado tempo de imersão das cascas de laranja no solvente para não prejudicar a quantidade de óleo extraída.

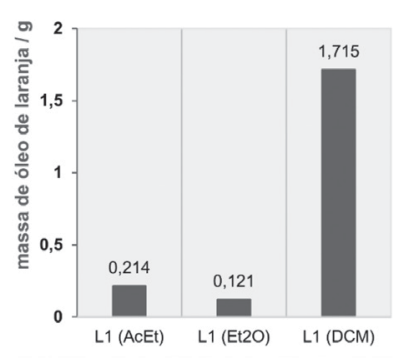

(a)

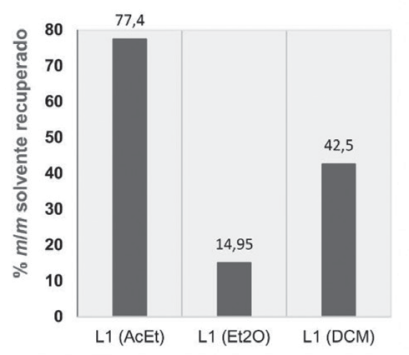

(c)

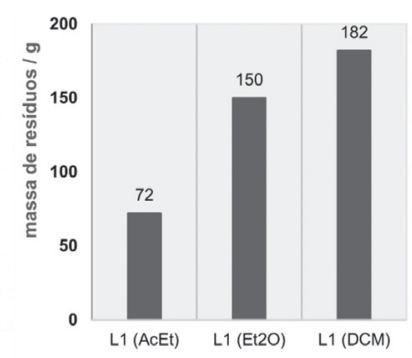

(b)

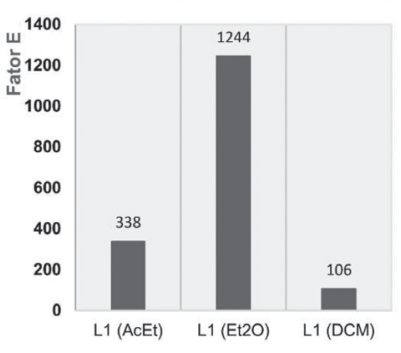

(d)
Figura 6. Valores obtidos no processo 2 (Extração com solvente) para (a) massa de óleo de laranja, (b) massa de resíduos, (c) percentagem massal massa de solvente recuperado e (d) fator $E$

A comparação dos resultados para os processos 1 e 2 mostra que o protocolo L1, em que se realiza a extração com DCM, é o que apresenta menor valor para o fator $\mathrm{E}$, o que se deve principalmente ao maior valor de BME. No entanto, a massa de óleo extraída foi baixa comparativamente com a quantidade de biomassa utilizada em ambos os processos (o valor máximo de BME não atingiu os 6\%), o que é de esperar face à baixa quantidade relativa de óleo na casca de laranja.

Para para a purificação da amostra comercial (processo 3) o rendimento obtido foi de $79 \pm 2 \%(n=4)$. $O$ valor determinado para o fator $E$ foi muito baixo $0,27 \pm 0,03(n=4)$, o que resulta de não se usarem substâncias auxiliares.

\section{Avaliação com métricas de tempo e de energia}

Nas operações de trituração das cascas de laranja e de destilação (processo 1) e de evaporação do solvente no evaporador rotativo (processo 2), a medição de energias e tempo permitiu o cálculo das respetivas métricas de intensidade, sendo os resultados apresentados na Figura 7.

No processo 1 (destilação por arrastamento de vapor), os protocolos D2-D4 apresentam os menores valores para a EI, logo, menor utilização de energia por grama de limoneno extraído. O protocolo D apresenta um valor de EI superior aos dos restantes (Figura 7), devido principalmente à pequena quantidade de limoneno obtido relativamente aos outros protocolos, já que a energia utilizada é semelhante para todos (Tabela 5S e 7S do Material Suplementar, secção 3.2.1.3). Pela mesma razão, no que se refere a TI, o protocolo D apresenta também um valor total superior aos restantes.

No processo 2 (extração com solventes), a utilização de energia ocorre durante a separação no evaporador rotativo. Os procedimentos em que se usa AcEt ou $\mathrm{Et}_{2} \mathrm{O}$ apresentam um valor de EI bastante superior ao do DCM (Figura 7), o que se deve principalmente à maior massa de óleo extraída neste último caso (Figura 5). O AcEt é
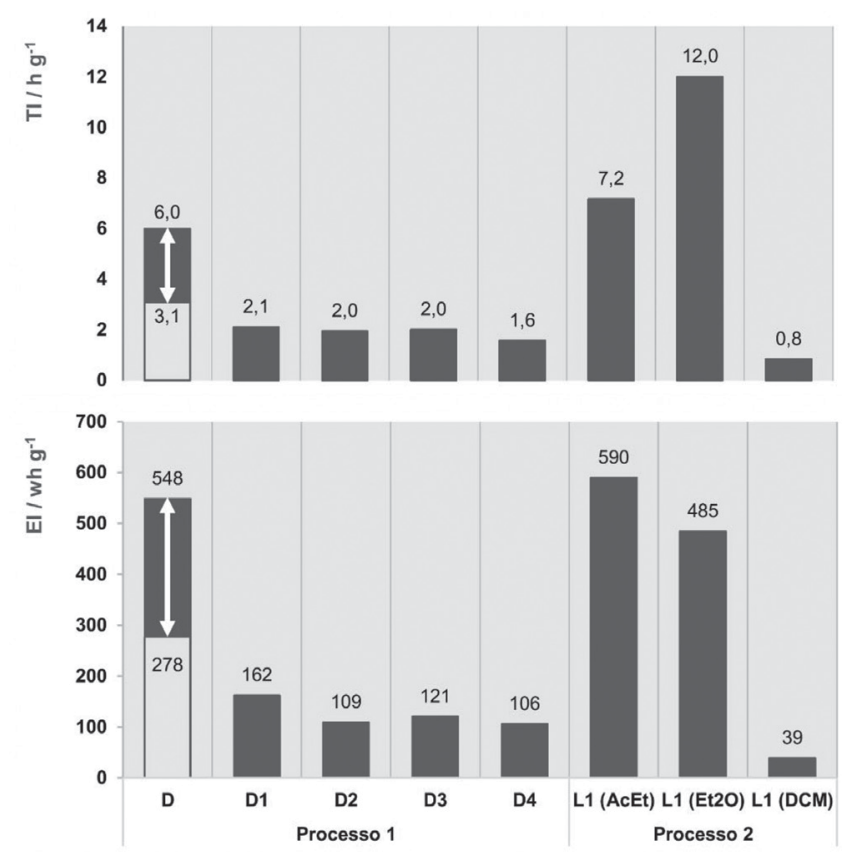

Figura 7. Valores da Intensidade de Energia (EI) e Intensidade de Tempo (TI) para o processo 1 (destilação por arrastamento de vapor): D-D4; e processo 2 (extração com solventes): L1(Solvente); para o protocolo D apresenta-se o intervalo de valores obtidos em quatro experiências $(\sharp)$

o solvente que envolve maior utilização de energia, por ser o menos volátil e, consequentemente, o mais difícil de remover por evaporação, daí que o valor obtido para o EI seja superior ao obtido para o $\mathrm{Et}_{2} \mathrm{O}$, embora a massa de óleo extraída seja superior. Comparando os dois processos, verifica-se que o menor valor de EI foi obtido para o processo 2 com DCM, o que se deve essencialmente à maior massa de óleo obtida por grama de matéria-prima.

Para o processo 3, referente à purificação da amostra comercial, obteve-se os valores EI $=123 \pm 20 \mathrm{Wh} \mathrm{g}^{-1}(\mathrm{n}=4)$ e $\mathrm{TI}=17,7 \pm 0,9$ $\min \mathrm{g}^{-1}(\mathrm{n}=4)$. Tanto quanto se explorou a literatura, esta não contém valores destas grandezas com que estes possam ser cotejados.

\section{Comparação dos processos de extração}

Na Tabela 6 apresenta-se um resumo dos resultados discutidos em detalhe acima. O negrito ou cor assinalam os melhores resultados obtidos para cada caso, evidenciando contradições entre as métricas quando se fazem comparações entre protocolos do mesmo tipo, por exemplo, D3 apresenta as melhores métricas de massa mas D4 as melhores métricas de energia e tempo. As causas e implicações destes conflitos serão evidenciadas na discussão a seguir.

A importância da gestão do tempo na prática industrial implica que seja importante maximizar a taxa de extração do óleo de laranja/ limoneno por unidade de tempo, de forma a obter a maior quantidade de óleo por grama de epicarpo de casca de laranja no menor tempo possível. Os resultados experimentais mostram que os protocolos mais eficazes para realizar a extração do óleo a partir da casca de laranja são: o protocolo D4, para o processo de extração por destilação por arrastamento de vapor; e o protocolo L1 (DCM), para a extração com solventes (ver Tabela 6). O melhor valor de BME (5,7\%) foi conseguido com o protocolo L1 (DCM), que apresenta também o melhor valor de throughput; no entanto, a destilação por arrastamento de vapor (D4, processo 1), devido ao menor tempo exigido na extração do óleo, pode executar-se em uma aula laboratorial (no processo de extração com solvente são necessárias duas aulas, entre as quais as cascas ficam a extrair). 
Tabela 6. Resumo dos resultados do trabalho experimental ${ }^{\alpha}$

\begin{tabular}{|c|c|c|c|c|c|c|c|}
\hline \multirow{2}{*}{$\mathrm{P}$} & \multirow{2}{*}{ Protocolo realizado } & \multirow{2}{*}{ EV (IPE) } & \multicolumn{5}{|c|}{ Métricas } \\
\hline & & & Fator E & BME & EI & $\mathrm{TI}$ & Throughput \\
\hline \multirow{4}{*}{ P1 } & D1 & 58,33 & 50 & 2,1 & 162 & 2,1 & 0,48 \\
\hline & D2 & & 53 & 2,0 & 110 & 2,0 & 0,51 \\
\hline & D3 & & 34 & 3,0 & 121 & 2,0 & 0,50 \\
\hline & D4 & & 37 & 2,8 & 106 & 1,6 & 0,64 \\
\hline \multirow{3}{*}{$\mathrm{P} 2$} & $\mathrm{~L} 1(\mathrm{AcEt})$ & 25,00 & 338 & 0,7 & 590 & 7,2 & 0,14 \\
\hline & $\mathrm{L} 1\left(\mathrm{Et}_{2} \mathrm{O}\right)$ & 25,00 & 1244 & 0,4 & 485 & 12,0 & 0,08 \\
\hline & L1(DCM) & 8,33 & 106 & 5,7 & 39 & $\mathbf{0 , 8}$ & 1,21 \\
\hline $\mathrm{P} 3$ & $\mathrm{~K}$ & 50,00 & 0,27 & - & 123 & 0,29 & 2,7 \\
\hline
\end{tabular}

Por outro lado, a gestão dos custos com a energia é também importante. Embora a extração com DCM, protocolo L1(DCM), apresente os melhores valores para EI e TI, outros aspetos desencorajam o uso deste procedimento: por um lado, os perigos do DCM para a saúde humana são elevados (em especial, H351 - suspeito de provocar cancro); por outro, o óleo extraído apresenta uma qualidade inferior à do obtido por destilação, exibindo contaminação com substâncias presentes na casca. Embora o fator E para a extração com DCM seja o mais baixo (ver a Tabela 6), os resíduos apresentam perigos elevados para a saúde. ${ }^{67-69}$ Este caso exemplifica uma situação vulgar quando se procura aumentar a verdura de um processo químico: sendo a verdura um conceito de natureza multidimensional, a procura do seu aumento em uma dimensão pode implicar diminuição em outra (ou outras), pelo que são requeridos compromissos nem sempre fáceis ou mesmo exequíveis.

Após este balanço, considerando que a água consumida na refrigeração pode ser reutilizada, o processo mais verde parece ser afinal a destilação por arrastamento de vapor, por apresentar menores riscos no manuseamento das substâncias e menor fator E, embora as métricas de massa sejam menos favoráveis que as da extração com DCM.

\section{Discussão sumativa}

A análise dos protocolos disponíveis na literatura para realizar a extração do limoneno das cascas de laranja e de outros obtidos pela sua alteração com vista a incrementar a verdura, realizada com a métrica $\mathrm{EV}$, revelou que o uso de solventes orgânicos prejudica significativamente a verdura, devido aos perigos para a saúde humana e o ambiente associados genericamente aos solventes propostos ou usados (pentano, hexano, éter de petróleo e DCM). Aquela avaliação sugere que a destilação por arrastamento de vapor, que não utiliza qualquer solvente orgânico, permite procedimentos mais verdes. No entanto, a avaliação de verdura dos protocolos realizada com outras métricas de diferentes tipos conduziu a resultados que, embora em parte conflituosos entre si, põem em causa esta conclusão.

Quando se aborda a metrificação da verdura em postura holística, não é invulgar encontrar situações em que diferentes métricas de verdura proporcionam resultados em conflito, o que evidencia a complexidade do conceito de verdura química e as dificuldades de concretizar a QV. O presente caso é um exemplo rico das dificuldades de lidar com tais situações que permite mostrar a importância da análise da verdura química ser realizada em paralelo com diversos tipos de métricas quantitativas, quer métricas de verdura "clássicas" (BME e fator E), quer outras mais ligadas a aspetos económicos da atividade industrial (throughput, EI e TI), bem como com métricas holísticas (como a EV). Na realidade, só o uso paralelo de diferentes métricas permite captar informação sobre diferentes coordenadas da verdura e obter uma visão mais global e realista das situações em estudo, o que possibilita a identificação de soluções de compromisso melhor fundamentadas em atividades de otimização da verdura. ${ }^{56}$ Este tema merece mais atenção do que a que lhe tem sido dada na literatura da QV, em especial a de natureza pedagógica, tendo este trabalho conduzido a resultados que ilustram bem a importância da multidimensionalidade das métricas e a necessidade de o assunto ser incluído no ensino da QV.

\section{CONCLUSÃO}

A análise e otimização da verdura dos protocolos de extração do óleo de laranja a partir das cascas encontrados na literatura educacional (destilação por arrastamento de vapor e extração com solvente) conduziu a um conjunto de resultados que permitem um bom aproveitamento para impulsionar o progresso da QV no contexto educacional, em especial no que diz respeito ao aprofundamento do conceito de verdura química - fazendo sentir a sua complexidade e as dificuldades da sua avaliação por meio de métricas.

O uso da metodologia adotada aqui para a realização experimental da extração de óleos essenciais constitui uma base para conceber atividades diversas para o ensino médio (anos terminais) e universitário, que incentivem um conhecimento aprofundado da verdura química, o que será bastante formativo na abordagem da QV. Em particular, fazer sentir aos alunos quanto a verdura química e a própria QV envolvem uma multiplicidade de dimensões com relações intrincadas, que implicam a consideração de uma grande variedade de aspetos para vencer as barreiras a ultrapassar quando se pretende reformatar a prática da química para obter QV, o que exige a adoção de raciocínio sistémico - sem prejuízo da racionalidade cartesiana vigente na ciência, mas sim em paralelo com esta.

\section{MATERIAL SUPLEMENTAR}

Detalhes sobre procedimentos experimentais e as Figuras 1S-12S e Tabelas 1S-12S estão disponíveis em http://www.quimicanova.sbq. org.br, em formato PDF, com acesso livre.

\section{AGRADECIMENTOS}

O trabalho de MGTCR e TCMP recebeu apoio financeiro da União Europeia (fundos FEDER POCI/01/0145/FEDER/007265) e de fundos nacionais (FCT/MEC, Fundação para a Ciência e Tecnologia e Ministério da Educação e Ciência) no âmbito do Acordo de Parceria PT2020 UID/QUI/50006/2013.

\section{REFERÊNCIAS}

1. Lin, C. S. K.; Pfaltzgraff, L. A.; Herrero-Davila, L.; Mubofu, E. B.; Abderrahim, S.; Clark, J. H.; Koutinas, A. A.; Kopsahelis, N.; 
Stamatelatou, K.; Dickson, F.; Thankappan, S.; Mohamed, Z.; Brocklesby, R.; Luque, R.; Energy Environ. Sci. 2013, 6, 426.

2. Clark, J. H.; Pfaltzgraff, L. A.; Budarin, V. L.; Hunt, A. J.; Gronnow, M.; Matharu, A. S.; Macquarrie, D. J.; Sherwood, J. R.; Pure Appl. Chem. 2013, 85, 1625.

3. Gallezot, P.; Chem. Soc. Rev. 2012, 41, 1538.

4. Coelho, M. A. Z.; Ribeiro, B. D.; White Biotechnology for Sustainable Chemistry. RSC: Cambridge, 2016.

5. Sanders, J.; Scott, E.; Weusthuis, R.; Mooibroek, H.; Macromol. Biosci. 2007, 7, 105.

6. Christensen, C. H.; Rass-Hansen, J.; Marsde, C. C.; Taarning, E.; Egeblad, K.; ChemSusChem 2008, 1, 283.

7. Pfaltzgraff, L. A.; De bruyn, M.; Cooper, E. C.; Budarin, V.; Clark, J. H.; Green Chem. 2013, 15, 307.

8. López, J. A. S.; Li, O.; P. Thompson, I. P.; Crit. Rev. Biotechnol. 2010, 30,63 .

9. Boukroufa, M; Boutekedjiret, C.; Petigny, L.; Njara Rakotomanomana,N.; Chemat, F.; Ultrason. Sonochem. 2015, 24, 72.

10. González-Rivera, J.; Spepi, A.; Ferrari, C.; Duce, C.; Longo, I.; Falconieri, D.; Piras, A.; Tinè, M. R..; Green Chem. 2016, 18, 6482.

11. Bica, K.; Gaertner, P.; Rogers, R. D.; Green Chem. 2011, 13, 1997.

12. Sterrett, F. S.; J. Chem. Educ. 1962, 39, 203.

13. Barros, F. M. C. d.; Zambarda, E. d. O.; Heinzmann, B. M.; Mallmann, C. A.; Quim. Nova 2009, 32, 861.

14. Alcântara, J. M.; Yamaguchi, K. K. d. L.; Junior, V. F. d. V.; Lima, E. S.; Quim. Nova 2010, 33, 141.

15. Tsukamoto, J.; Durán, N.; Tasic, L.; J. Braz. Chem. Soc. 2013, 24, 1537.

16. Bizzo, H. R.; Hovell, M. C.; Rezende, C. M.; Quim. Nova 2009, 32, 588.

17. Sterrett, F. S.; J. Chem. Educ. 1962, 39, 246.

18. http://www.floridachemical.com/whatisd-limonene.htm, acessada em outubro de 2017.

19. Mattos, M. C. S. d.; Bernini, R. B.; J. Braz. Chem. Soc. 2007, 18, 1068.

20. Júnior, M. R. M.; Pastore, G. M.; Quim. Nova 2007, 30, 382.

21. Surburg, H.; Panten, J.; Common Fragrance and Flavor Materials: Preparation, Properties and Uses, $5^{\text {th }}$ ed., Wiley-VCH Verlag $\mathrm{GmbH} \&$ Co., 2006.

22. Firdaus, M.; Meier, M. A. R.; Green Chem. 2013, 15, 370.

23. http://www.floridachemical.com/App\%20Page\%20Combined.pdf, acessada em outubro de 2017.

24. Júnior, C. V.; Quim. Nova 2003, 26, 390.

25. Baser, K. H. C.; Demirci, F. In Kirk-Othmer Encyclopedia of Chemical Technology, John Wiley and Sons, Inc., 2011; pp 1-37.

26. Beatty, J. H.; J. Chem. Educ. 1986, 63, 768.

27. Shahidi, F.; Zhong, Y., In Kirk-Othmer Encyclopedia of Chemical Technology, John Wiley and Sons, Inc., 2012; pp 1-17.

28. Sun, J.; Altern Med Rev 2007, 12, 259.

29 Figueiredo, I. M.; Santos, L. V. d.; Costa, W. F. d.; Carvalho, J. E. d.; Silva, C. C. d.; Sacoman, J. L.; Kohnb, L. K.; Sarragiotto, M. H.; J. Braz. Chem. Soc. 2006, 17, 954.

30. Lenardão, E. J.; Freitag, R. A; Dabdoub; M. J.; Batista, A. C. F.; Silveira, C. C.; Quim. Nova 2003, 26, 123.

31. Machado, A. A. S. C.; Quim. Nova 2011, 34, 535.

32. Greenberg, F. H.; J. Chem. Educ. 1968, 45, 537.

33. Griffin, R. W.; J. Chem. Educ. 1974, 51, 601.

34. Glidewell, C.; J. Chem. Educ. 1991, 68, 267.

35. Logan, J. L.; Rumbaugh, C. E.; J. Chem. Educ. 2012, 89, 613.

36. Epstein, J. L.; Castaldi, M.; Patel, G.; Telidecki, P.; Karakkatt, K.; J. Chem. Educ. 2015, 92, 954.

37. Garner, C. M.; Garibaldi, C.; J. Chem. Educ. 1994, 71, A146.

38. Rothenberger, O. S.; Krasnoff, S. B.; Rollins, R. B.; J. Chem. Educ. 1980, 57,741 .

39. Baptistella, L. H. B.; Imamura, P. M.; Melo, L. V. d.; Castello, C.; Quim. Nova 2009, 32, 1069.
40. Buckley, H. L.; Beck, A. R.; Mulvihill, M. J.; Douskey, M. C.; J. Chem. Educ. 2013, 90, 771.

41. McKenzie, L. C.; Thompson, J. E.; Sullivan, R.; Hutchison, J. E.; Green Chem. 2004, 6, 355.

42. Kulkarni, P. S.; Brazinha, C.; Afonso, C. A. M.; Crespo, J. G.; Green Chem. 2010, 12, 1990.

43. http://www.cedefop.europa.eu/files/3057_en.pdf, acessada em outubro de 2017.

44. Haack, J. A.; Hutchison, J. E.; ACS Sustainable Chem. Eng. 2016, 4, 5889.

45. Bergstrom, W.; Howells, M., Advanced Chemistry Laboratory Experiments. University of Minnesota, 1988.

46. http://resources.schoolscience.co.uk/ICI/periodictable/downloads/ smellpracs.pdf, acessada em outubro de 2017.

47. Smith, D. C.; Forland, S.; Bachanos, E.; Matejka, M.; Barrett, V.; Chem. Educator 2001, 6, 28.

48. Afonso, C. A. M.; Simão, D. P.; Ferreira, L. P.; Serra, M. E. d. S.; Raposo, M. M. M.; 100 Experiências de Química Orgânica. IST Press, 2011.

49. Ribeiro, M. G. T. C.; Costa, D. A.; Machado, A. A. S. C.; Quim. Nova 2010, 33, 759 .

50. Ribeiro, M. G. T. C.; Costa, D. A.; Machado, A. A. S. C.; Green Chem. Lett. Rev. 2010, 3, 149.

51. Ribeiro, M. G. T. C.; Yunes, S. F.; Machado, A. A. S. C.; J. Chem. Educ. 2014, 91, 1901.

52. Sheldon, R. A.; Green Chem. 2007, 9, 1273.

53. Sheldon, R. A.; Green Chem. 2017, 19, 18.

54. Sheldon, R. A.; Chem. Ind. 1992, 23, 903.

55. Machado, A. A. S. C.; Introdução às métricas da Química Verde: uma visão sistémica. Editora UFSC, 2014.

56. Machado, A. A. S. C.; Quim. Nova 2011, 34, 1291.

57. Zhang, T. Y.; Chem. Rev. 2006, 106, 2583.

58. Butters, M.; Catterick, D.; Craig, A.; Curzons, A.; Dale, D.; Gillmore, A.; Green, S. P.; Marziano, I.; Sherlock, J.-P.; White, W.; Chem. Rev. 2006, 106, 3002.

59. ht t p: / / eur-1ex.europa.eu/LexUriServ/Lex UriServ. do?uri=CELEX:32008R1272:EN:NOT, acessada em outubro de 2017.

60. http://educa.fc.up.pt/catalogo/pt/separacoes/1/1, acessada em outubro de 2017.

61. http://educa.fc.up.pt/catalogo/pt/separacoes/1/1/A, acessada em outubro de 2017.

62. http://educa.fc.up.pt/catalogo/pt/separacoes/1/1/B, acessada em outubro de 2017

63. http://educa.fc.up.pt/catalogo/pt/separacoes/1/1/C, acessada em outubro de 2017.

64. http://educa.fc.up.pt/catalogo/pt/separacoes/1/1/D, acessada em outubro de 2017

65. http://educa.fc.up.pt/catalogo/pt/separacoes/1/1/E, acessada em outubro de 2017.

66. http://educa.fc.up.pt/catalogo/pt/separacoes/1/1/F, acessada em outubro de 2017.

67. http://educa.fc.up.pt/catalogo/pt/separacoes/1/1/G, acessada em outubro de 2017.

68. http://educa.fc.up.pt/catalogo/pt/separacoes/1/1/H, acessada em outubro de 2017.

69. http://educa.fc.up.pt/catalogo/pt/separacoes/1/1/I, acessada em outubro de 2017.

70. http://educa.fc.up.pt/catalogo/pt/separacoes/1/1/J, acessada em outubro de 2017.

71. http://educa.fc.up.pt/catalogo/pt/separacoes/1/1/K, acessada em outubro de 2017. 